\title{
Populous: A tool for Populating OWL Ontologies from Templates
}

Simon Jupp

Bio Health Informatics Group, School of Computer Science, University of Manchester, UK

10.12.2010 SWAT4LS 2010, Berlin. 


\section{Ontology development} barriers

- The underlying representation

- The art of modeling

- Community engagement

- The tool support 


\section{Templates approach}

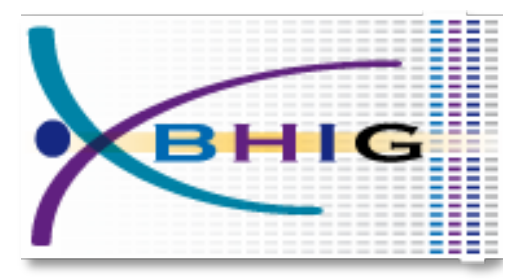

- Shield the underlying technology

- Collect repetitive information consistently

- Put constraints on the input data

- Abstraction from any complex modeling 


\section{Capturing the differentia}

All Eukarytoic Cells are either nucleated or anucleate, some cells are

Knowledge multinucleate

Ontologically

'Eukarytoic Cells' has_nucleation some 'Nucleation'

'Nucleation' subClass of \{mononucleate, binucleate , polynucleate , anucleate\}

Differentia

'Eukarytoic Cells' has_nucleation some 'Nucleation'

'Nucleation' subClass of \{mononucleate, binucleate, polynucleate, anucleate

\begin{tabular}{|c|c|c|}
\hline & 'Eukarytoic Cells' & 'Nucleation' \\
\hline Real Examples & $\begin{array}{l}\text { Mononculear phagocyte } \\
\text { Flight Muscle cell } \\
\text { Red Blood cell }\end{array}$ & $\begin{array}{l}\text { mononcuelate } \\
\text { multinucleate } \\
\text { anucleate }\end{array}$ \\
\hline
\end{tabular}




\section{Spreadsheets}

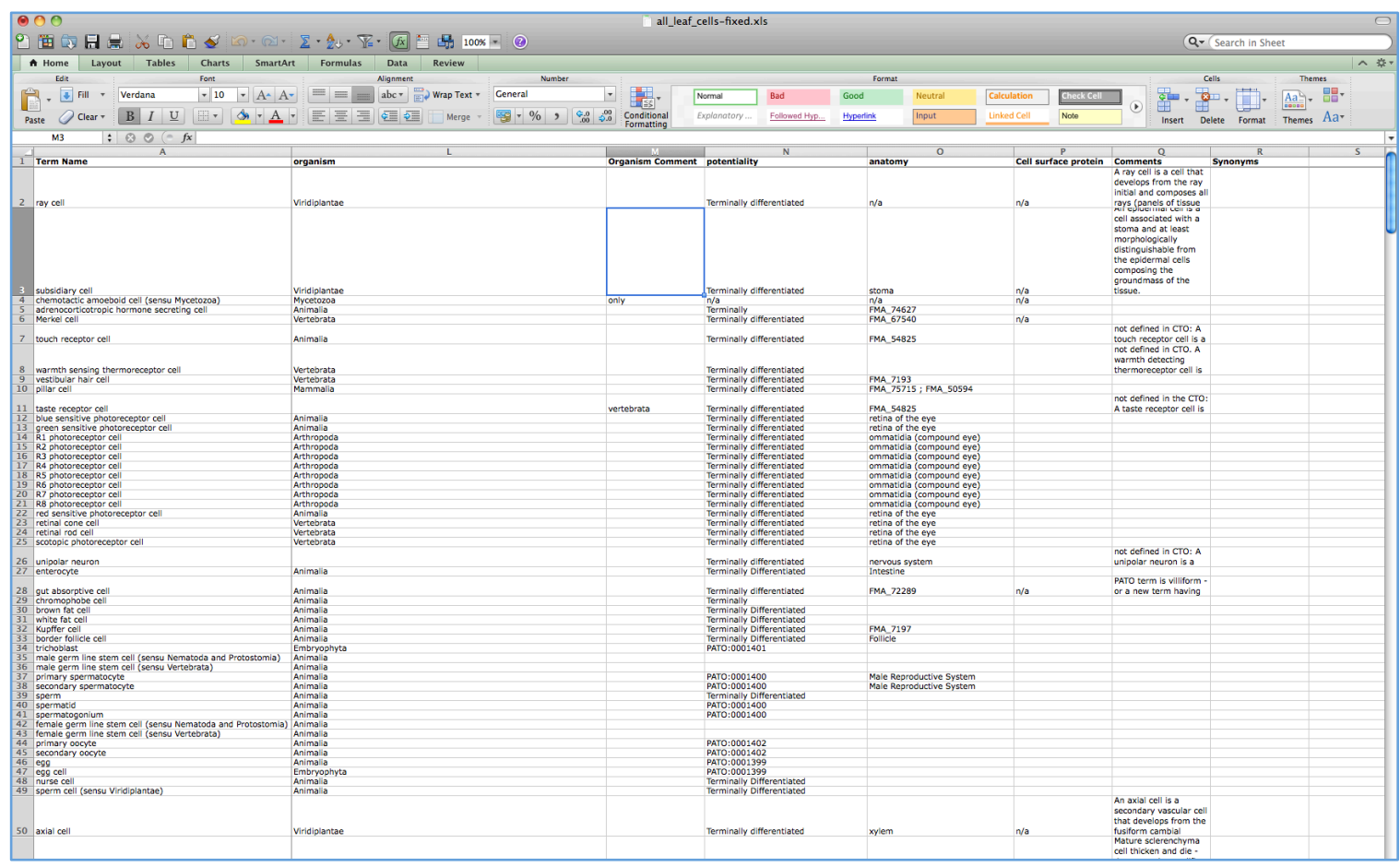

- A popular tool for data management

- Good at collecting regular data

- Users from many domains 


\section{Related work}

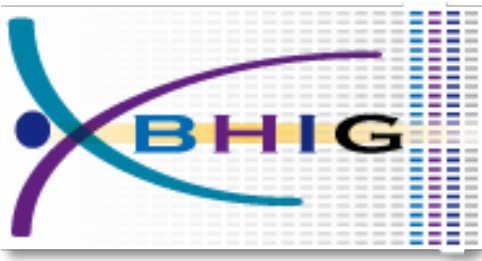

- Cell type ontology normalisation

- OBI and Quick Term Templates

- ICD-11

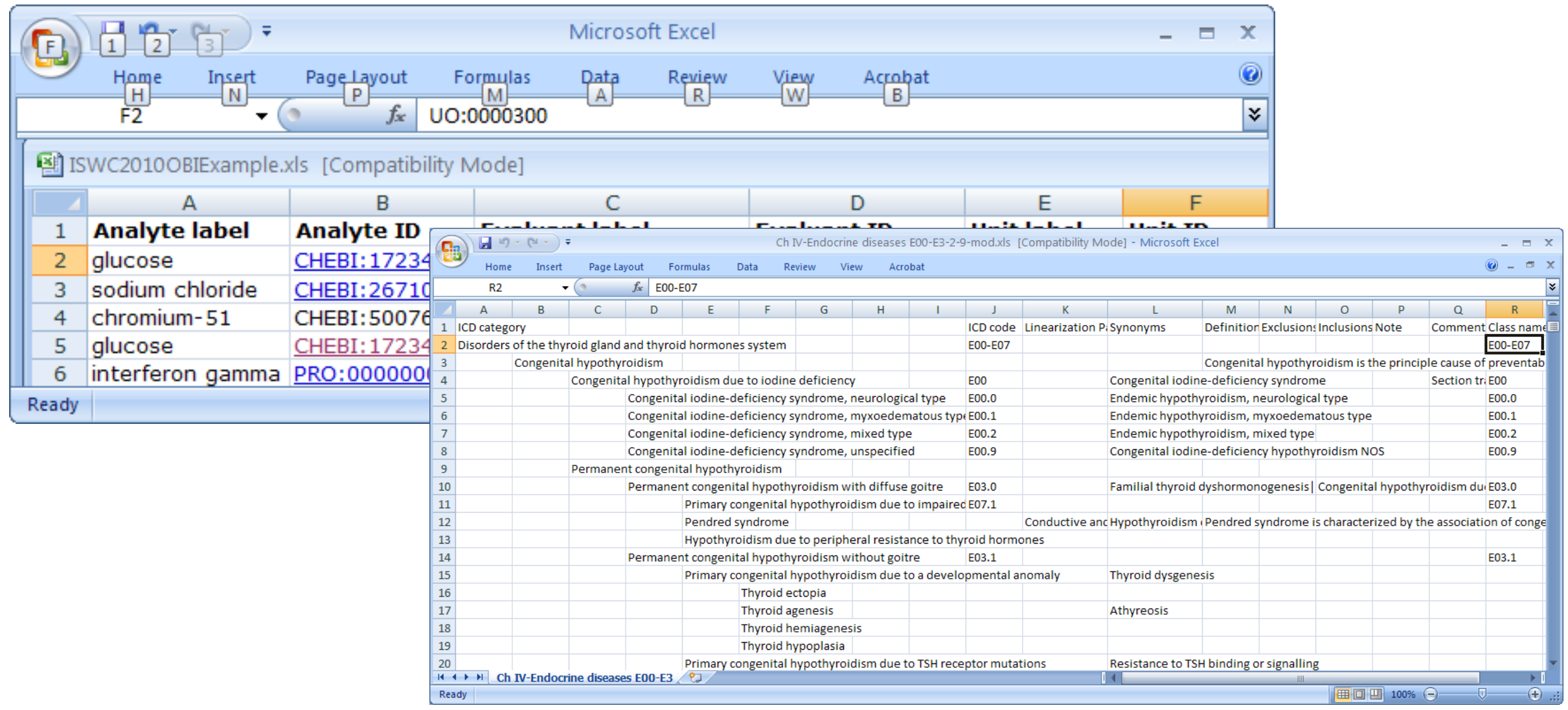



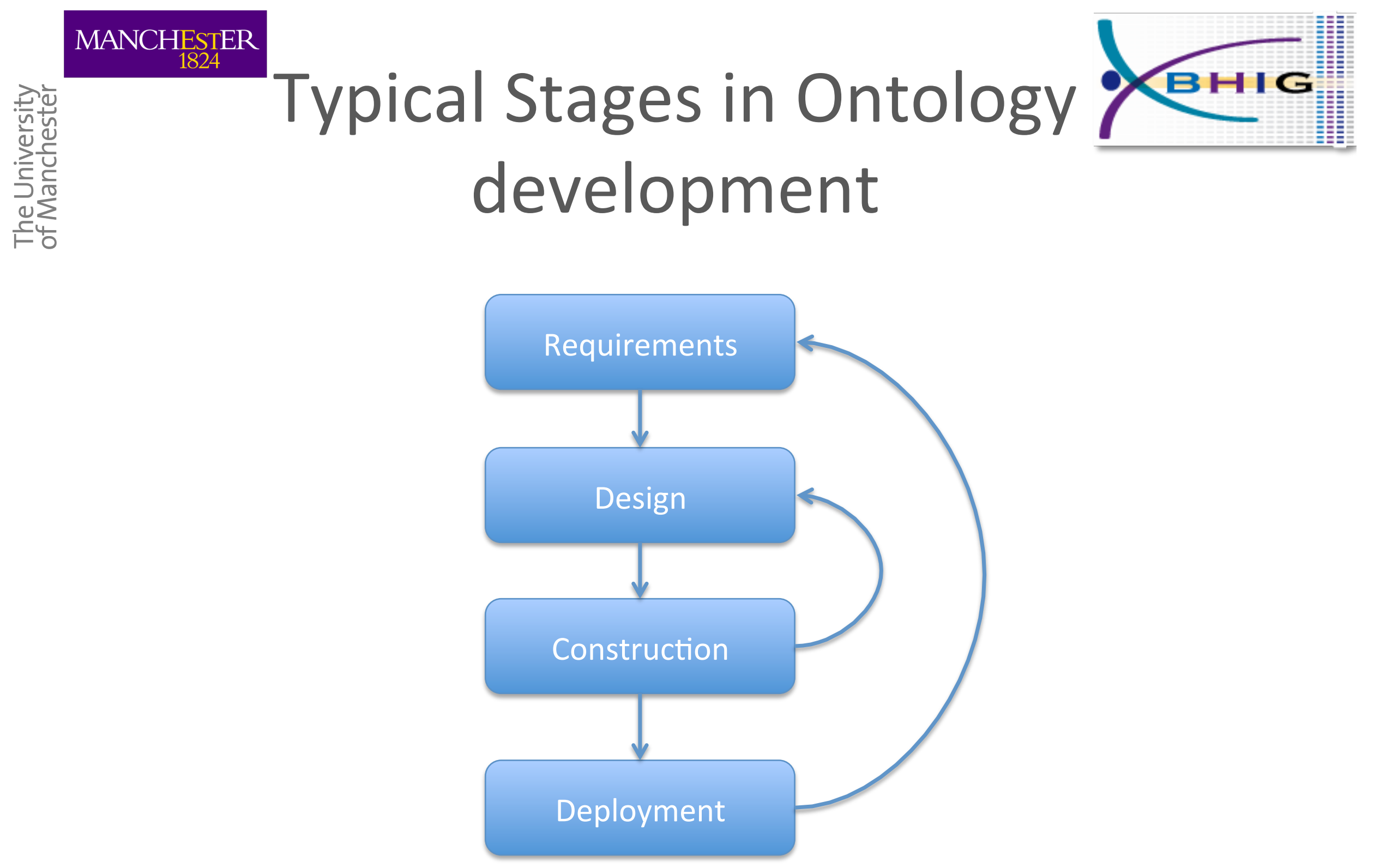

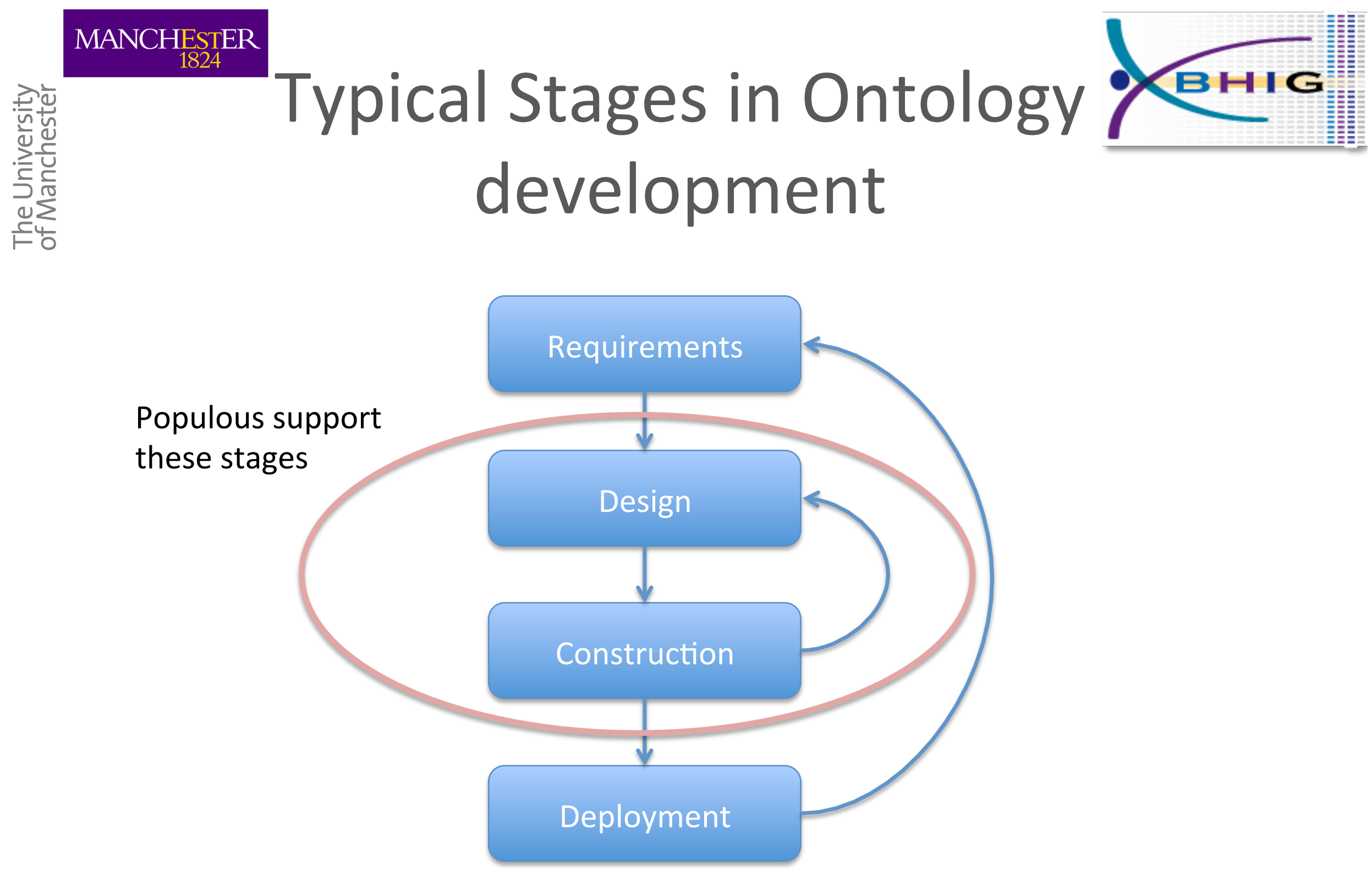


\section{Previous work}

- RDF based tools

- Excel2RDF, Convert2RDF, RDF123

- Protégé 4.0 plugins

- Excel Importer, Matrix Plugin

- Protégé 3.4

- Mapping Master (Protégé 3) 


\section{Populous}

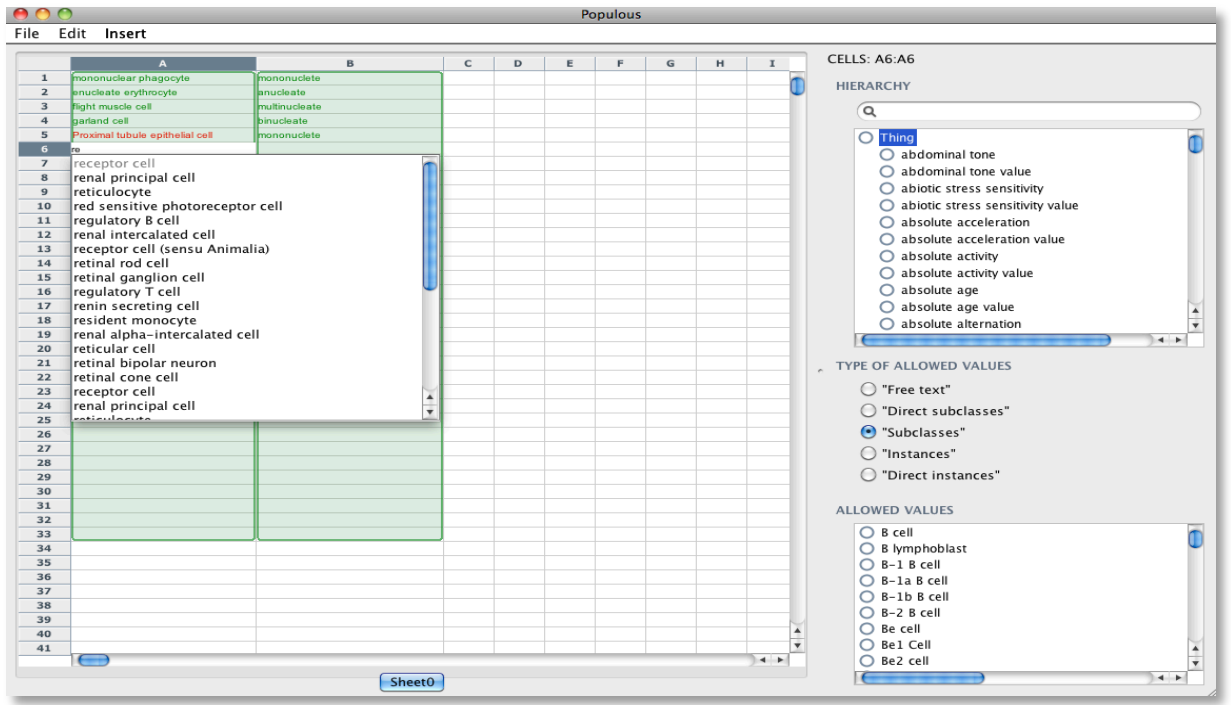

http://www.e-lico.eu/populous

- Generic tool for populating ontology templates

- Spreadsheet style interface

- Supports validation at the point of data entry

- Expressive Pattern language for OWL Ontology generation 


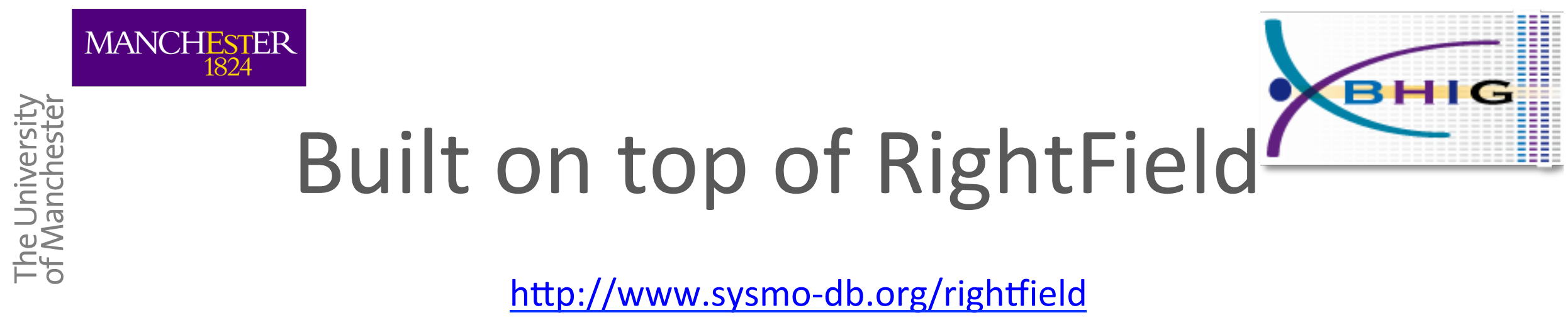

- Semantic Annotation by Stealth

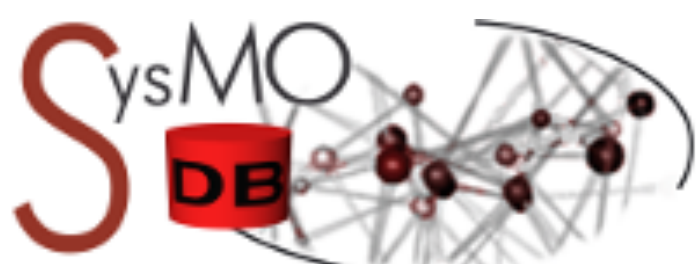

Systems Biology of Microorganisms
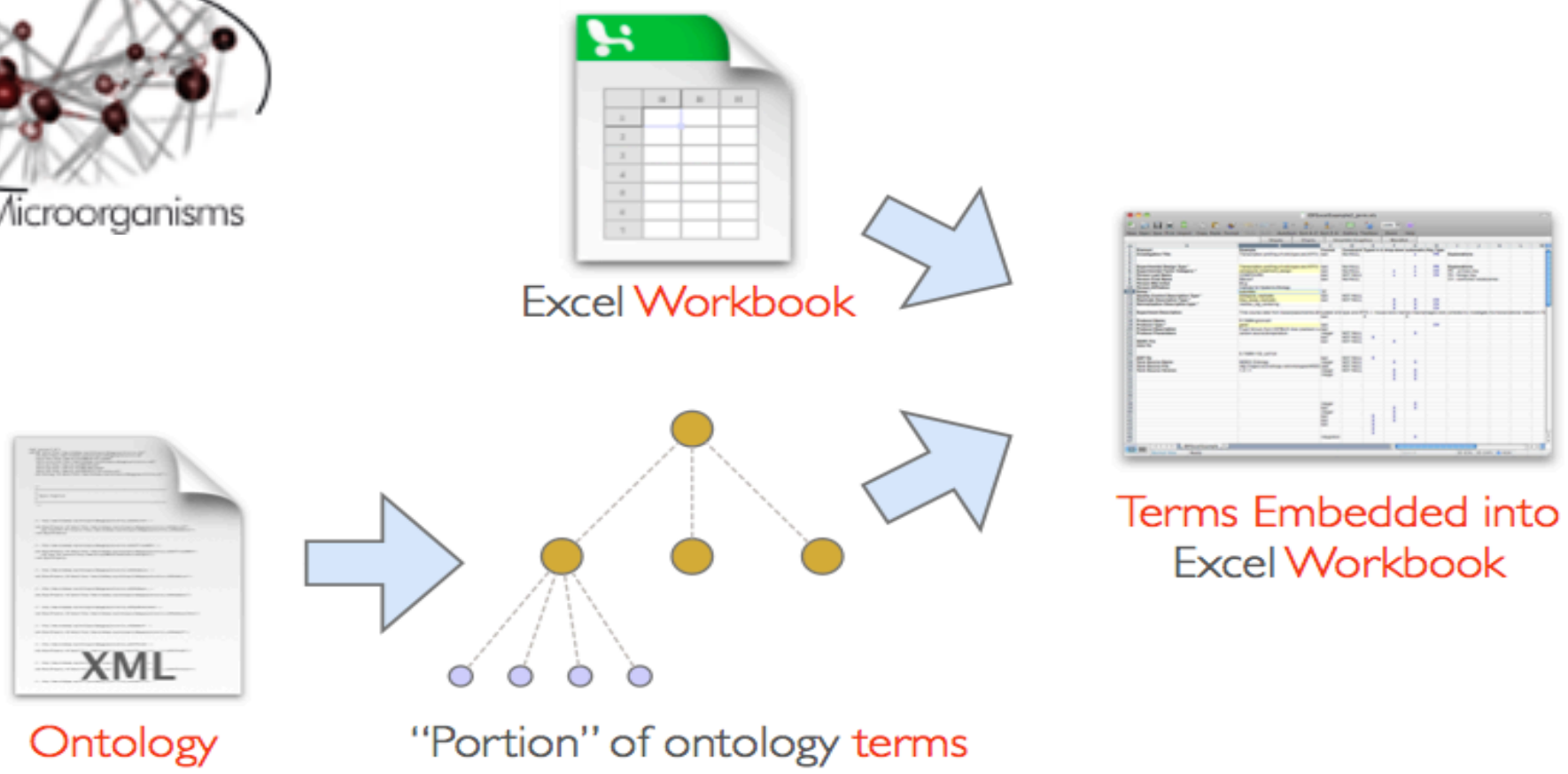

Terms Embedded into Excel Workbook 
MANCHESTER

1824

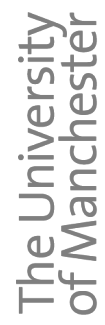

\section{Export to Excel}

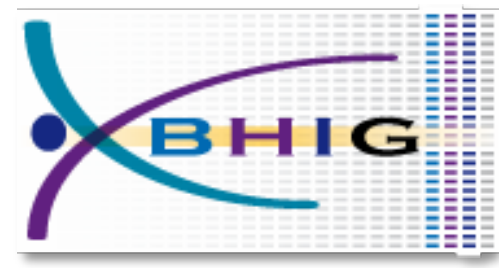

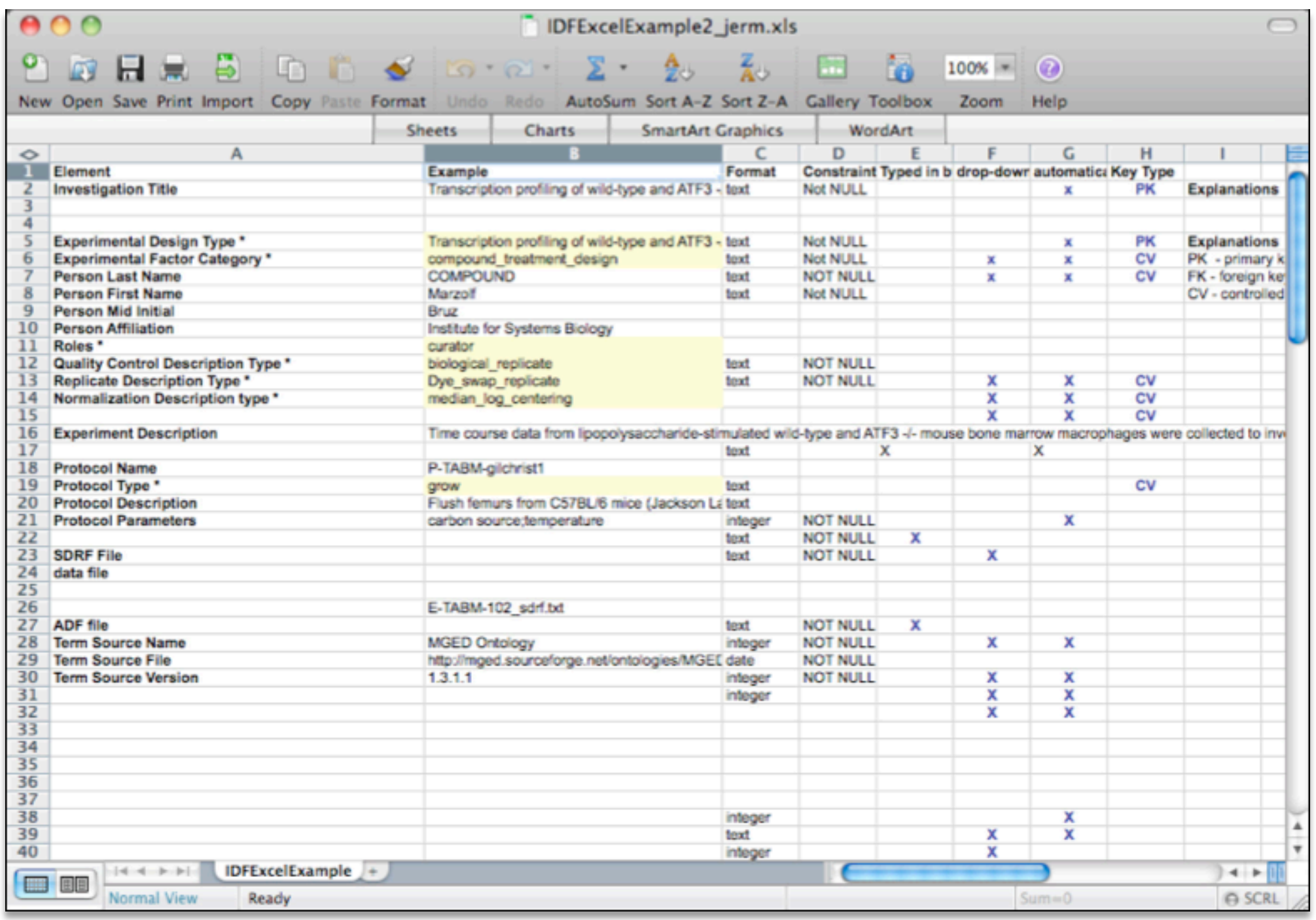




\section{Excel Validations}

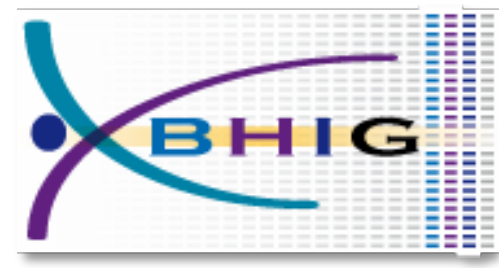

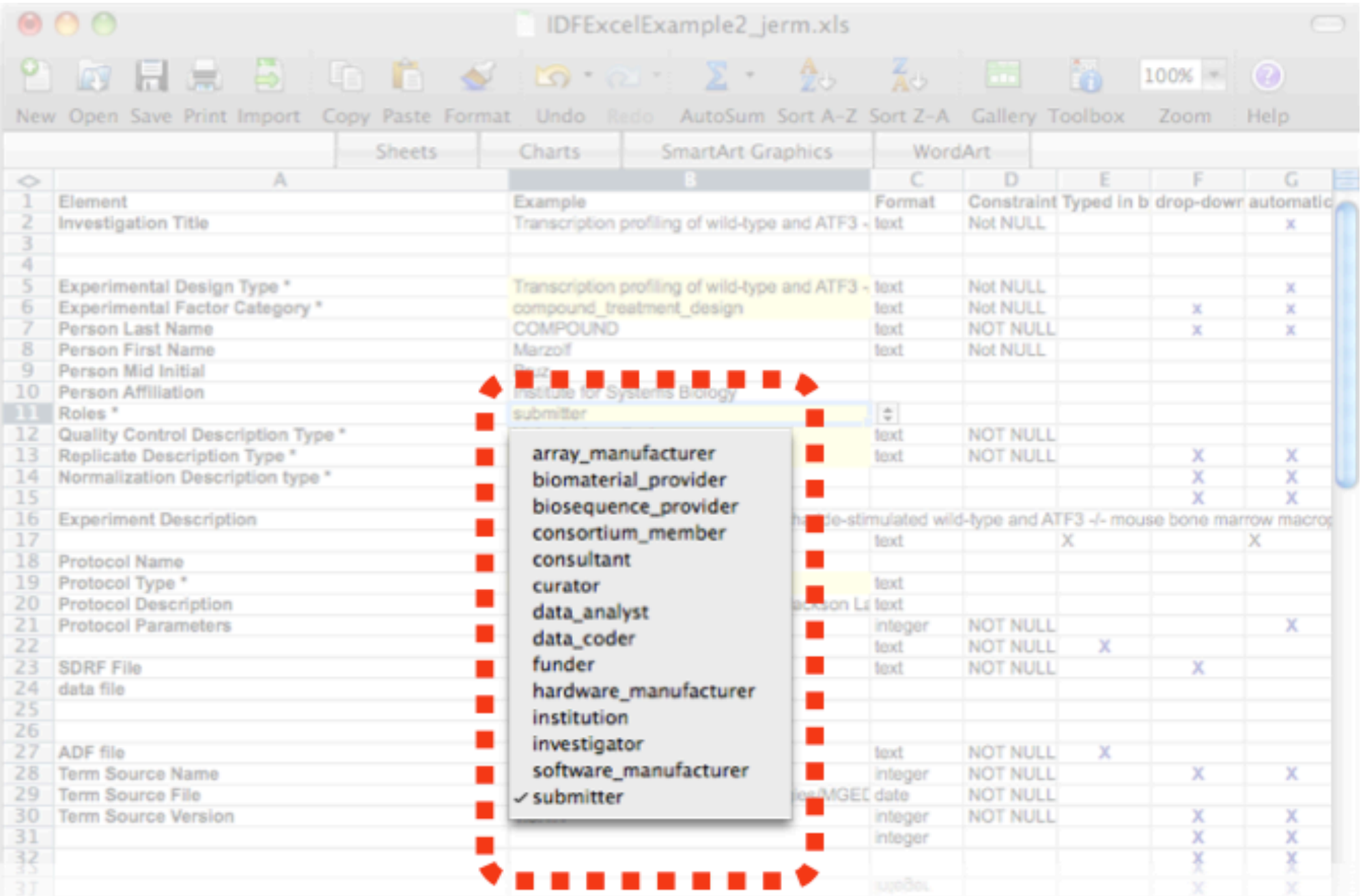




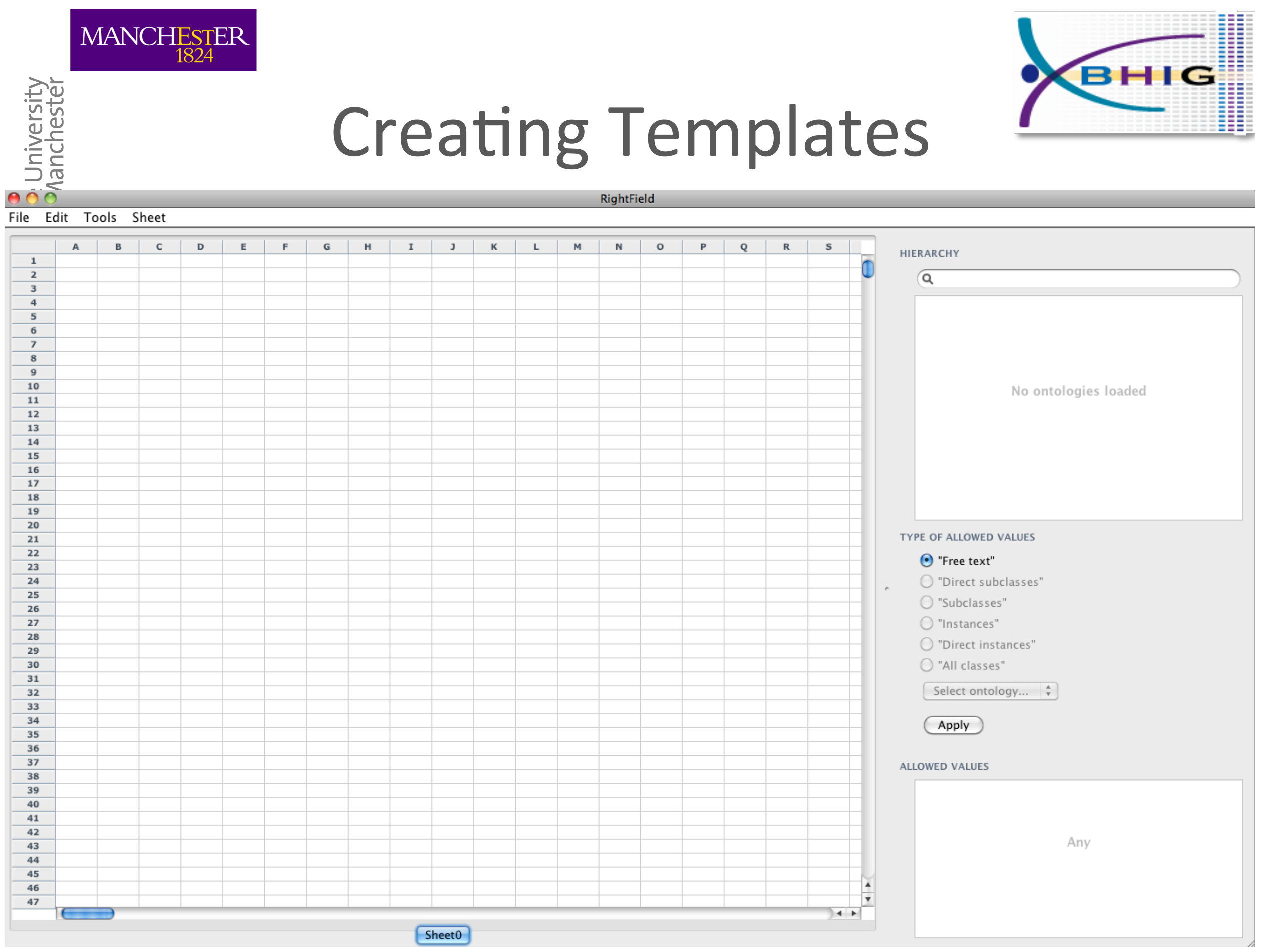




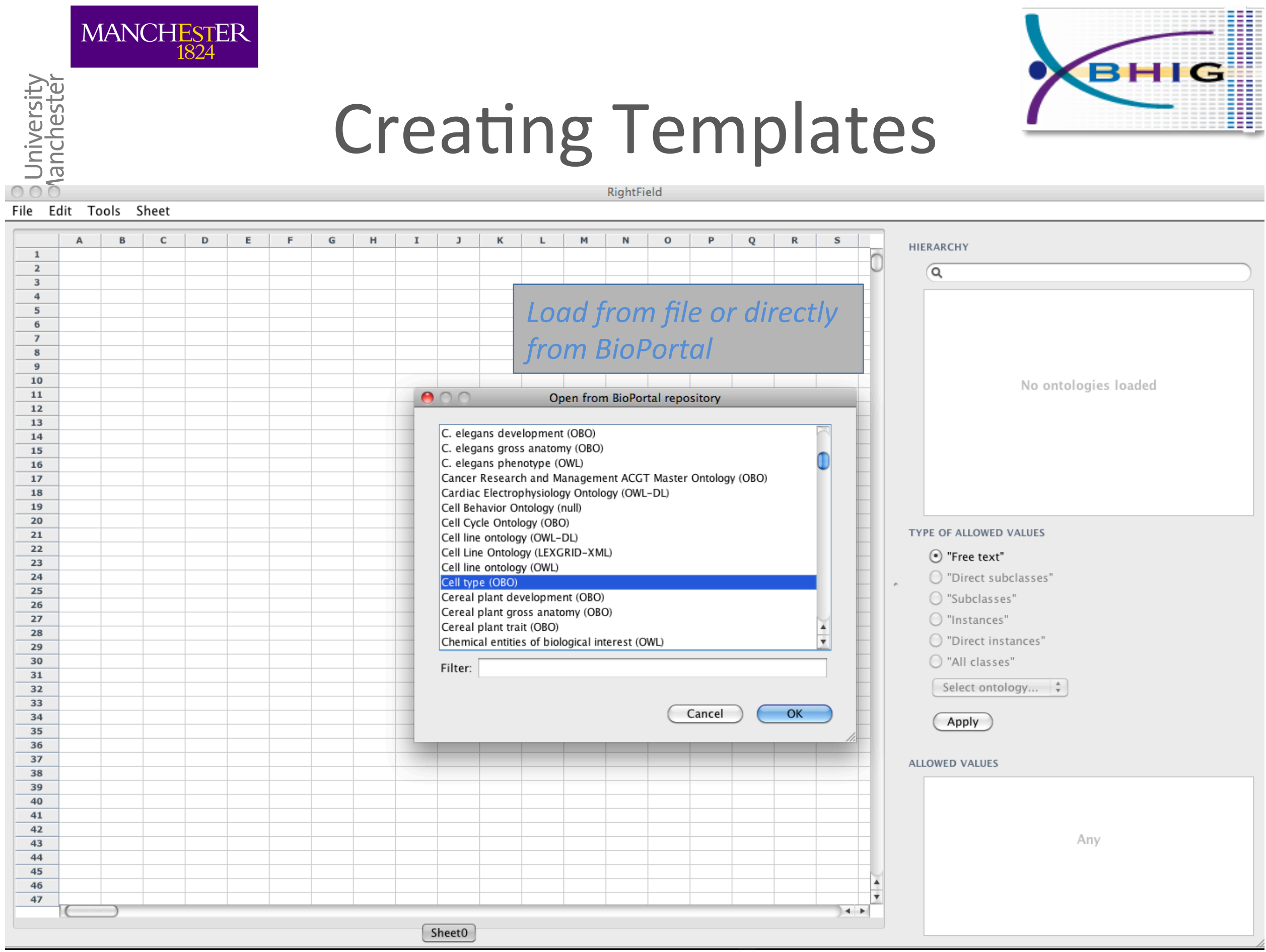




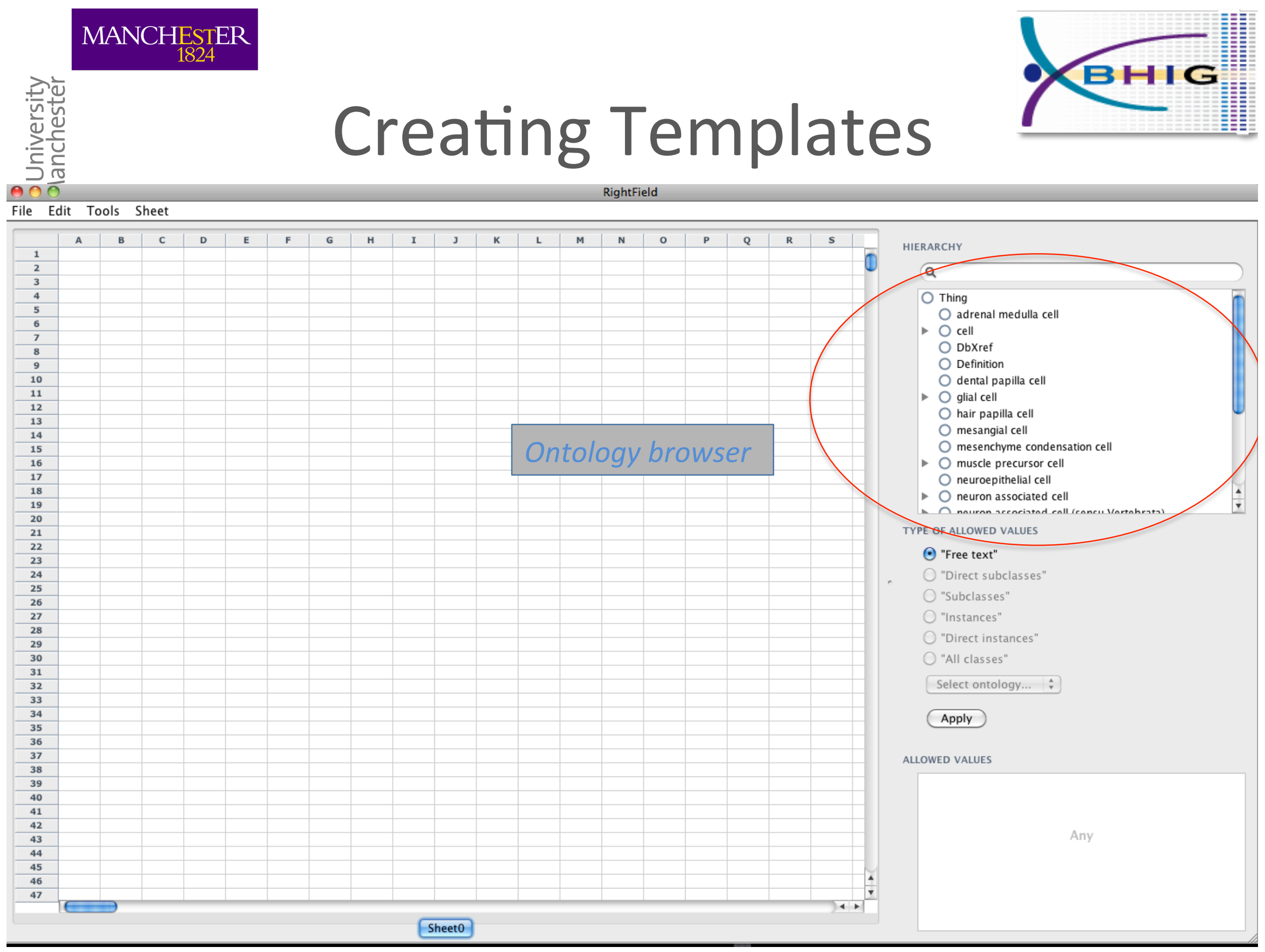




\section{Creating Templates}

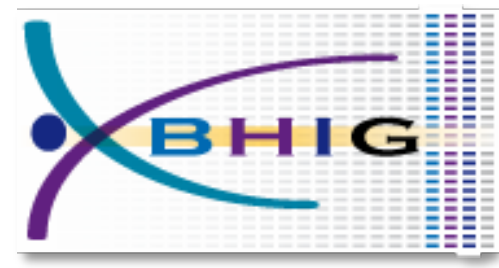

000

File Edit Tools Sheet

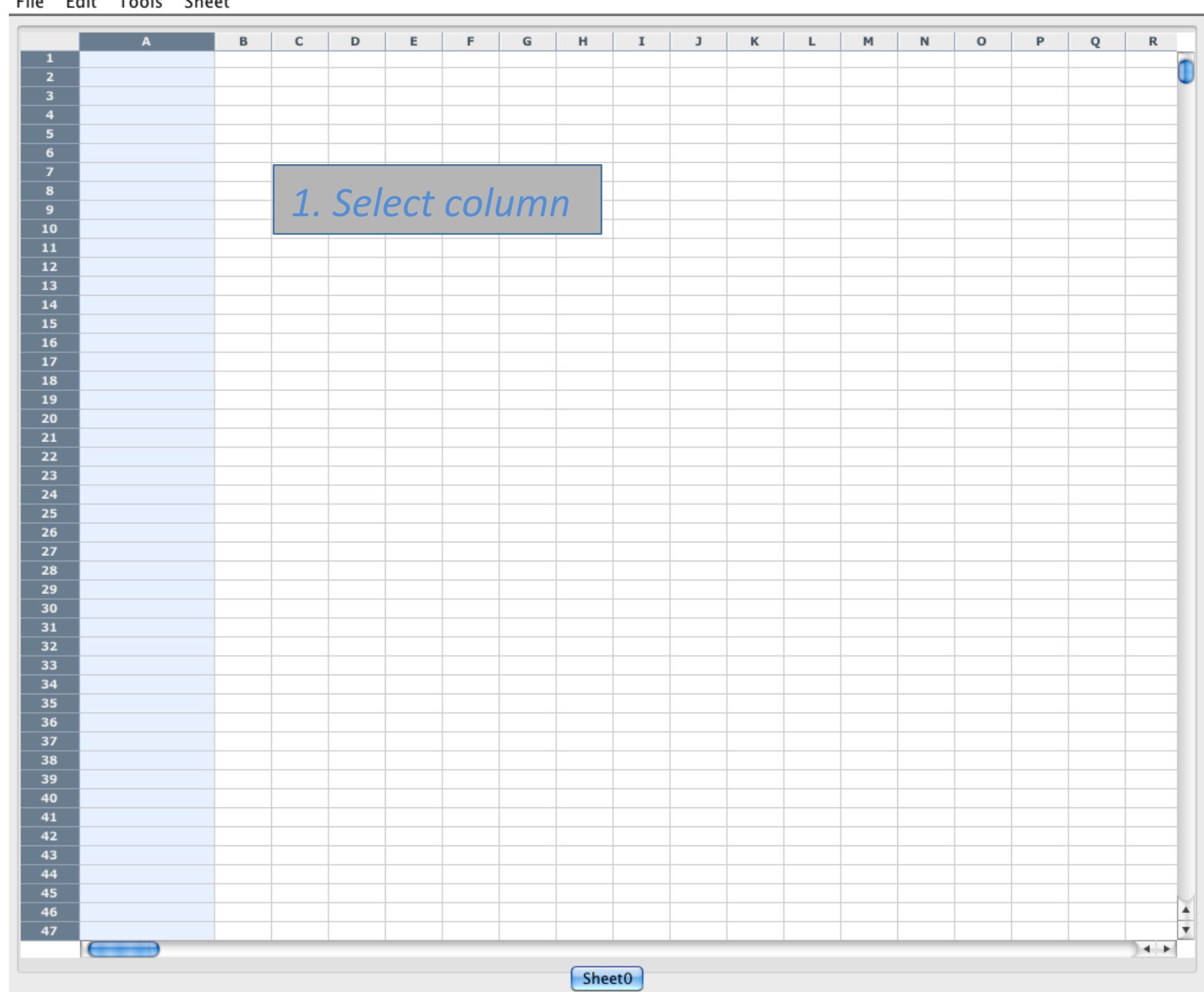

CELLS: A1:A32767

(1) hierarchy 


\section{Creating Templates}

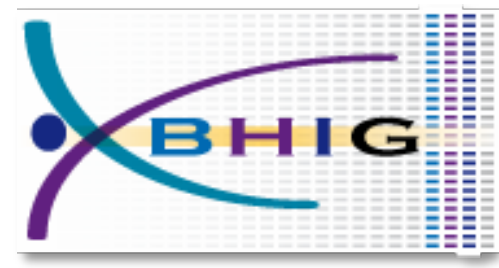

RightField

\section{File Edit Tools Sheet}

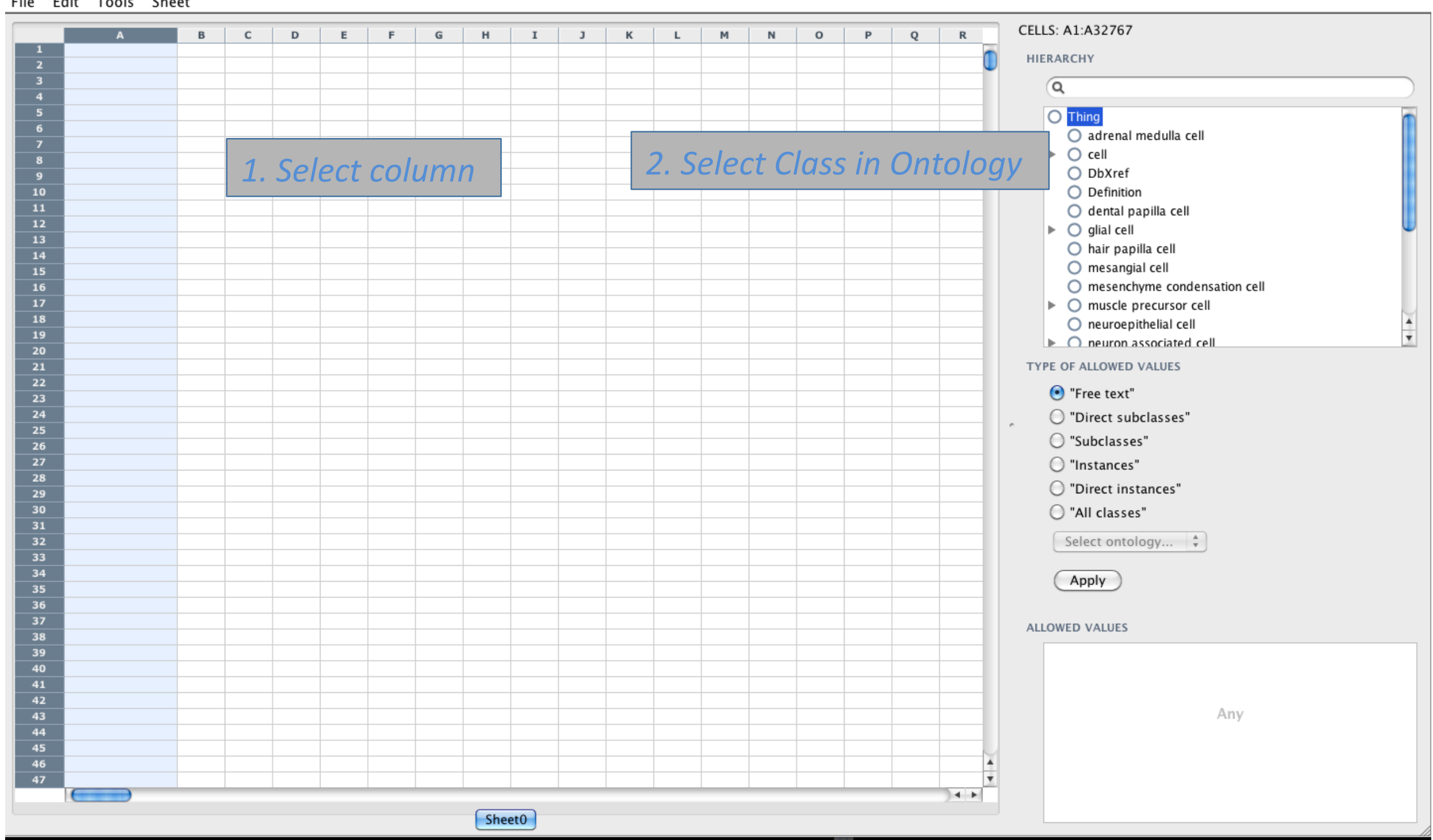




\section{Creating Templates}

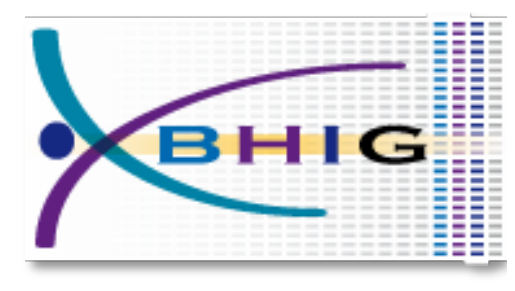

ब०

File Edit Tools Sheet

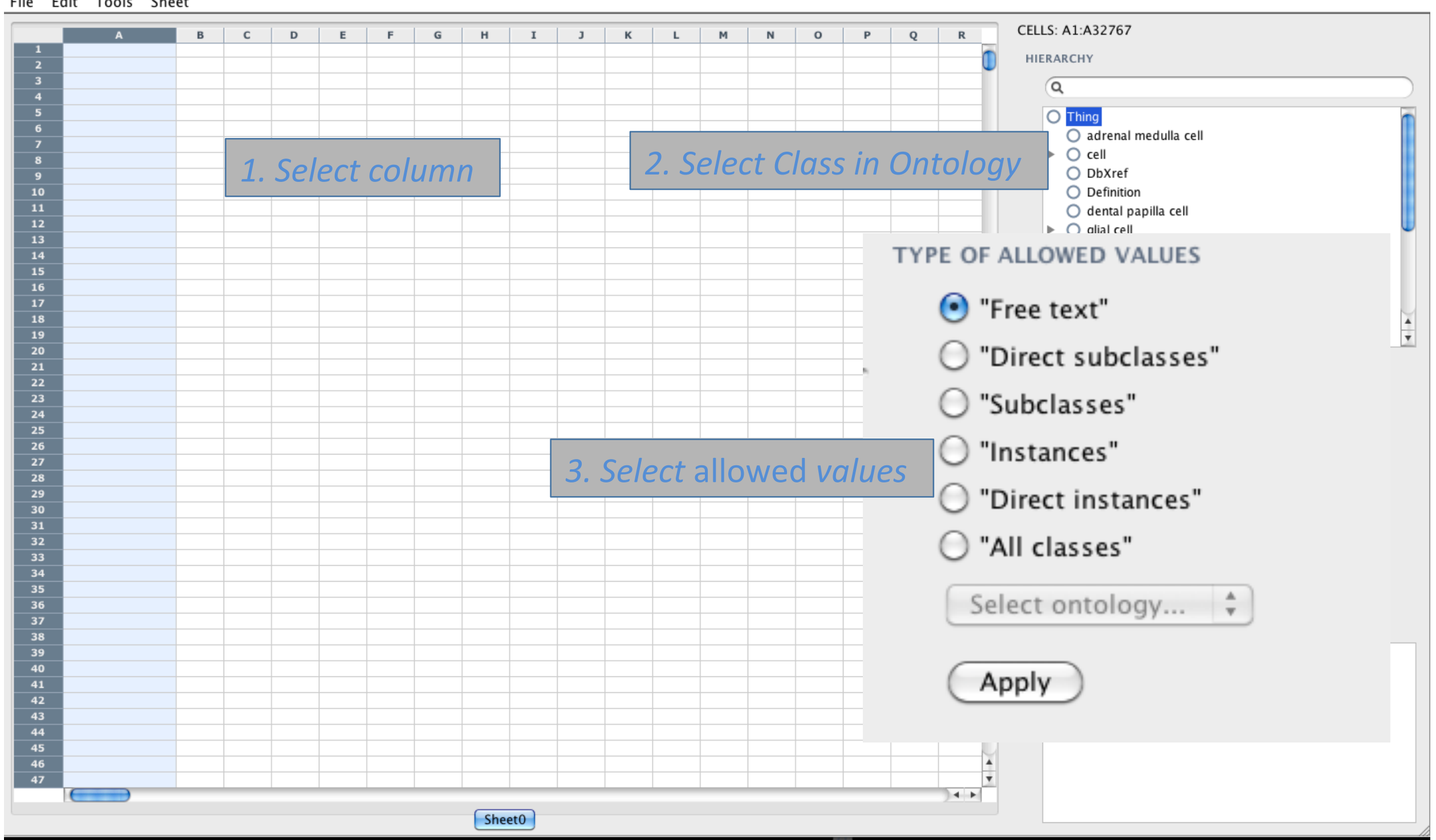




\section{Creating Templates}

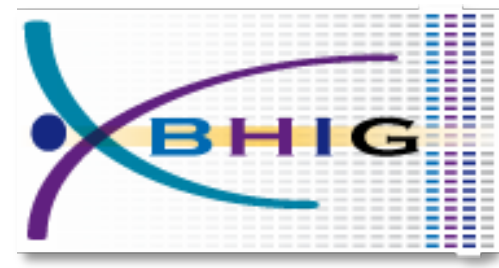

RightField

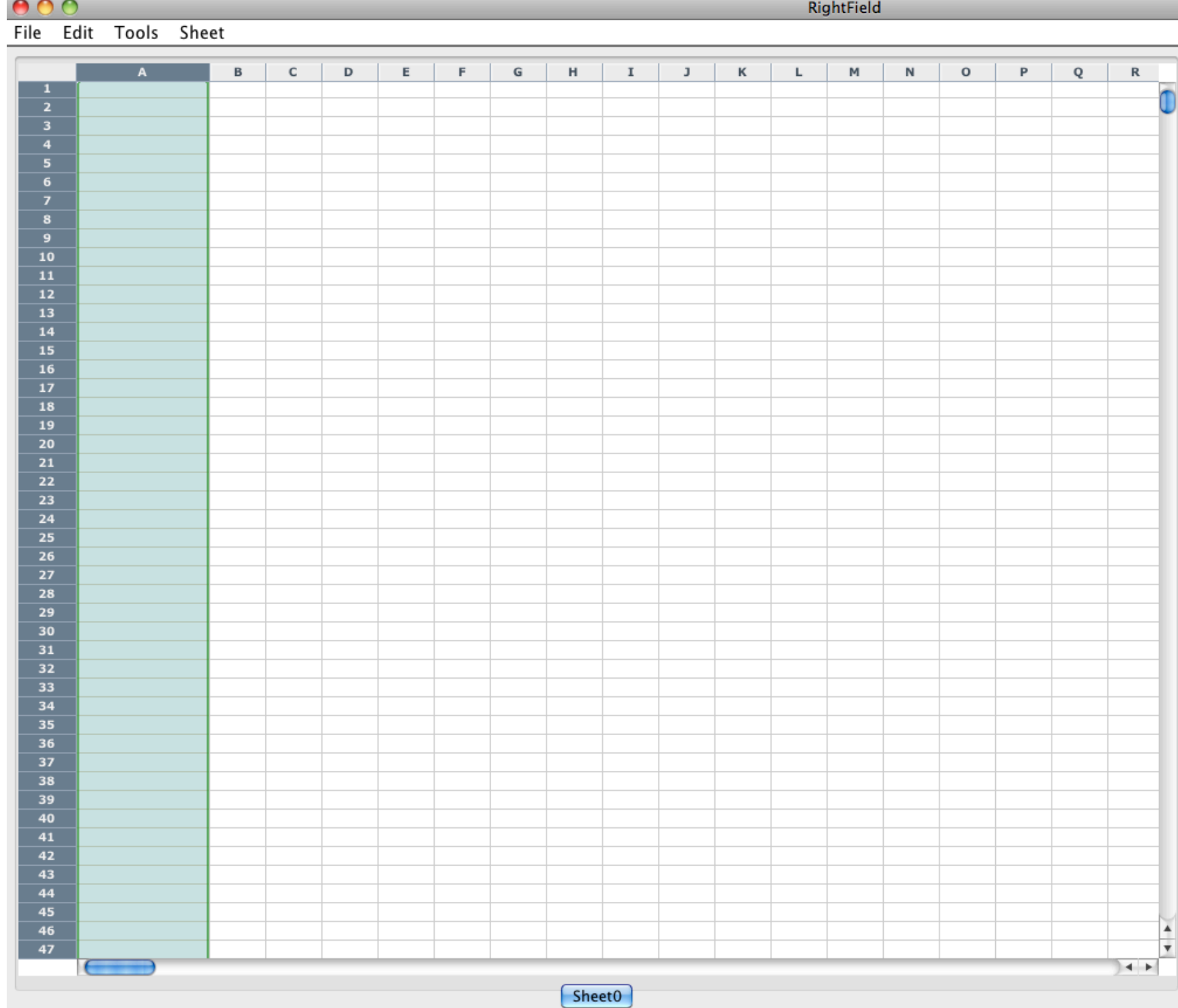

CELLS: A1:A32767

(1) Hierarchy

Q Thing

O adrenal medulla cell

-O cell

DbXref

Definition
dental papilla ce

O glial cell

hair papilla cell

mesangial cell

O mesenchyme condensation cell

muscle precursor cell

O neuroepithelial cell

- neuron associated cell

TYPE OF ALLOWED VALUES

$\bigcirc$ "Free text"

"Direct subclasses"

"Subclasses"

"Instances"

"Direct instances"

"All classes"

Select ontology...

\section{Apply}

ALLOWED VALUES

$O$ B cell
B-1 B cell
B-1a B cell
$O$ B-1b B cell
B-2 B cell
$\bigcirc$ Be cell
$\bigcirc$ Be1 Cell
$\bigcirc$ Be2 cell
Bm1 B cell


MANCHESTER

1824

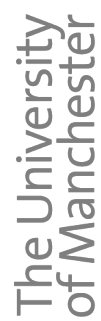

\section{Editing Templates}

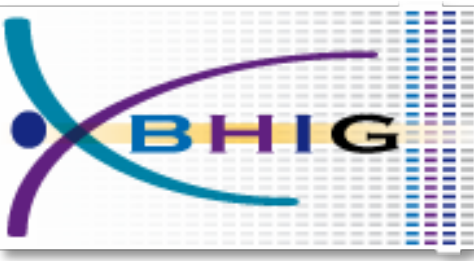

Populous

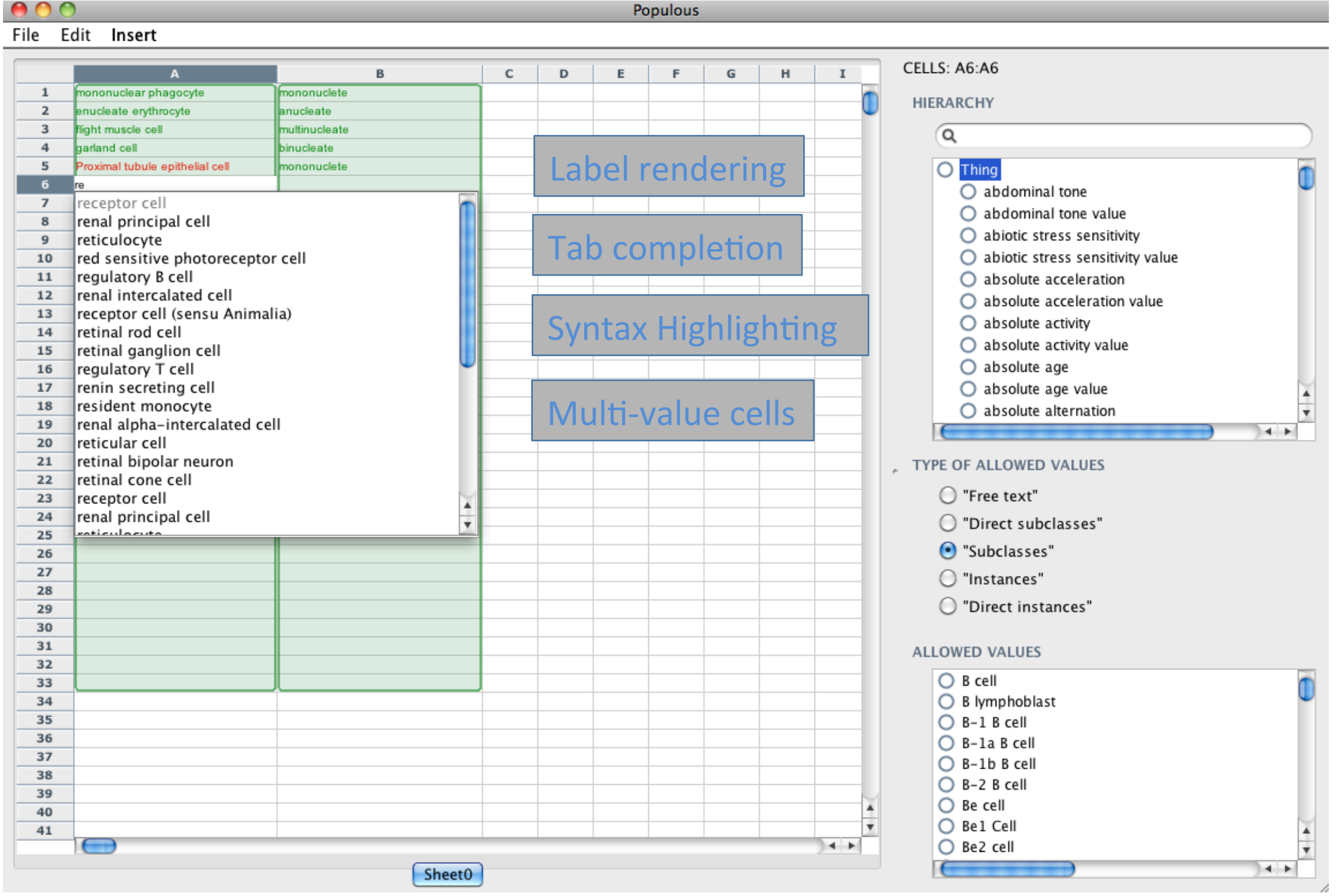


MANCHESTER

1824

\section{Editing Templates}

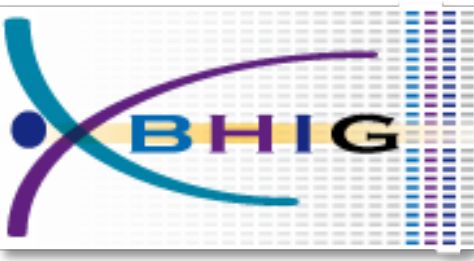

Populous

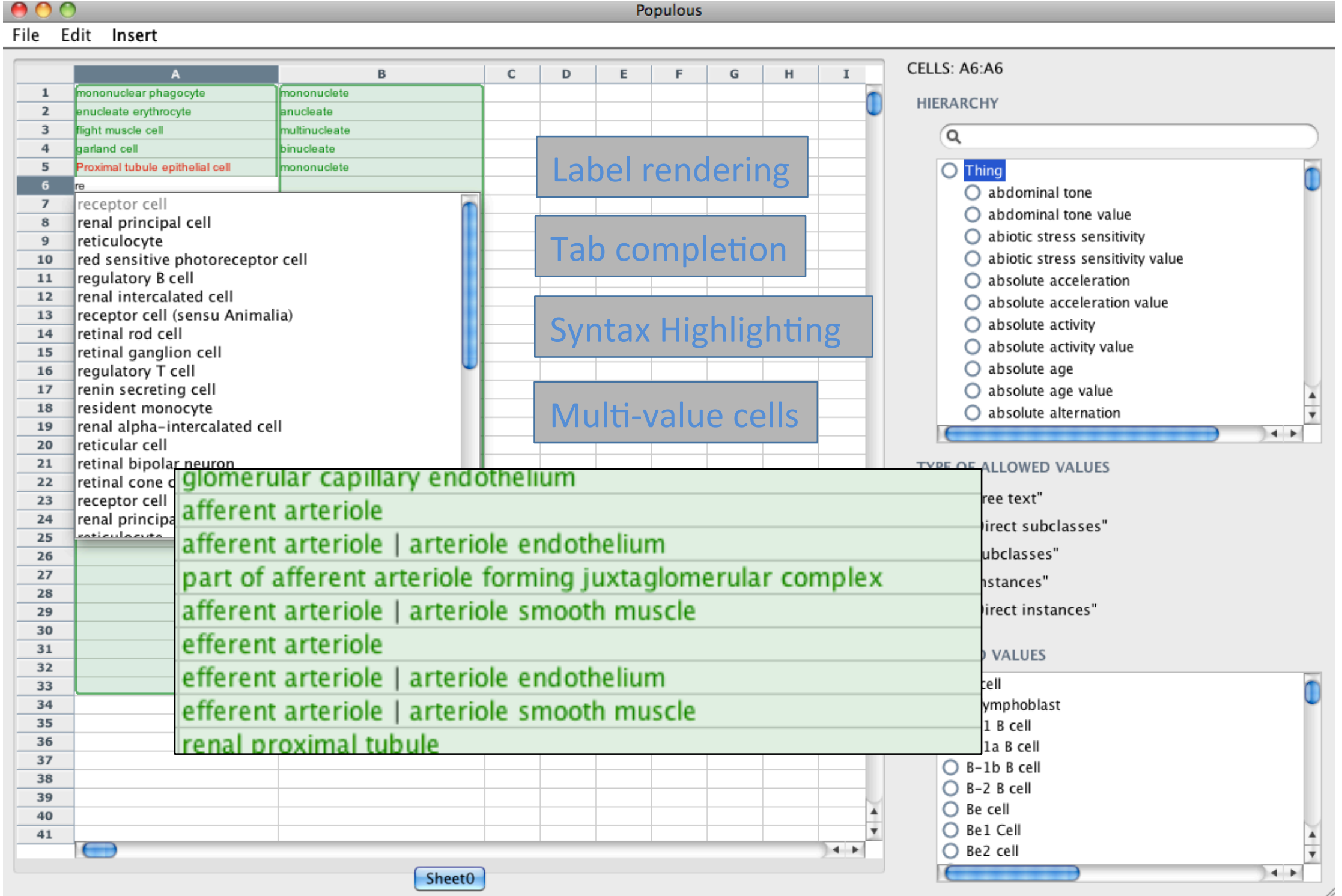




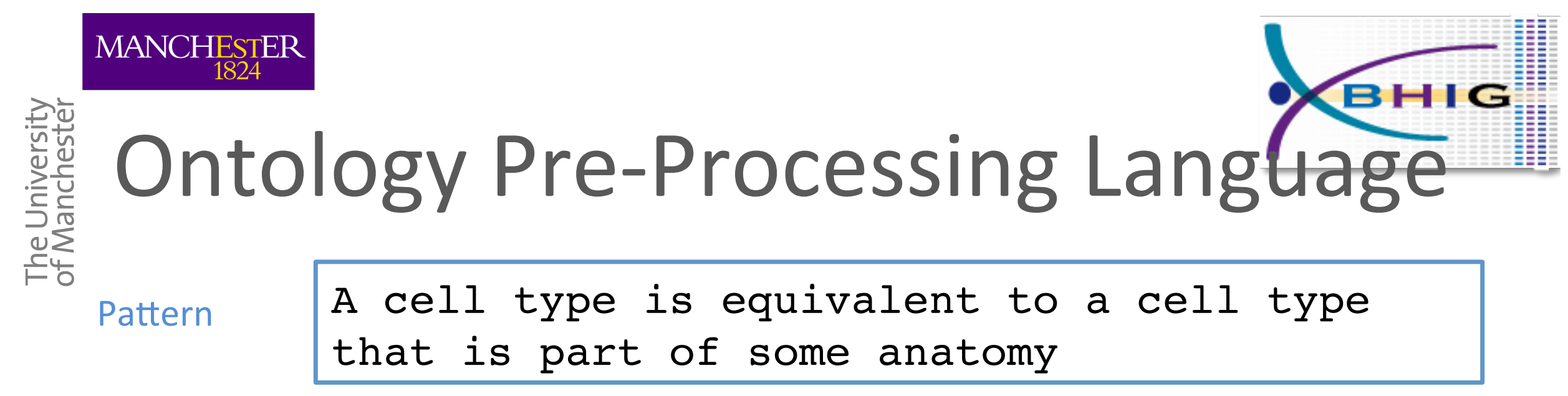




\section{Ontology Pre-Processing Langtrage}

A cell type is equivalent to a cell type that is part of some anatomy

?cell:CLASS,
?anatomyPart:CLASS,
?anatomy:CLASS =
(CL:0000000 part_of some ?anatomyPart)
BEGIN
ADD ?cell equivalentTo ?anatomy
END;




\section{Ontology Pre-Processing LangGrage}

A cell type is equivalent to a cell type that is part of some anatomy

Variable mapper

?cell -> 'Kidney Cell' [CL:0003523]

?anatomyPart $\rightarrow>$ 'Kidney' [FMA:629093]

?cell : CLASS,

?anatomyPart:CLASS,

?anatomy: CLASS =

OPPL Script

(CL:0000000 part_of some ?anatomyPart)

BEGIN

ADD ?cell equivalentTo ?anatomy END; 


\section{Resulting OWL axioms}

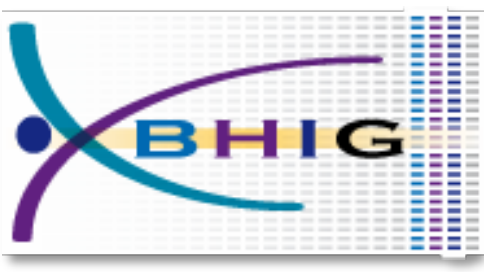

A 'Kidney Cell' is equivalent to a cell that is part of the 'Kidney'

\section{Generated OWL (Manchester Syntax)}

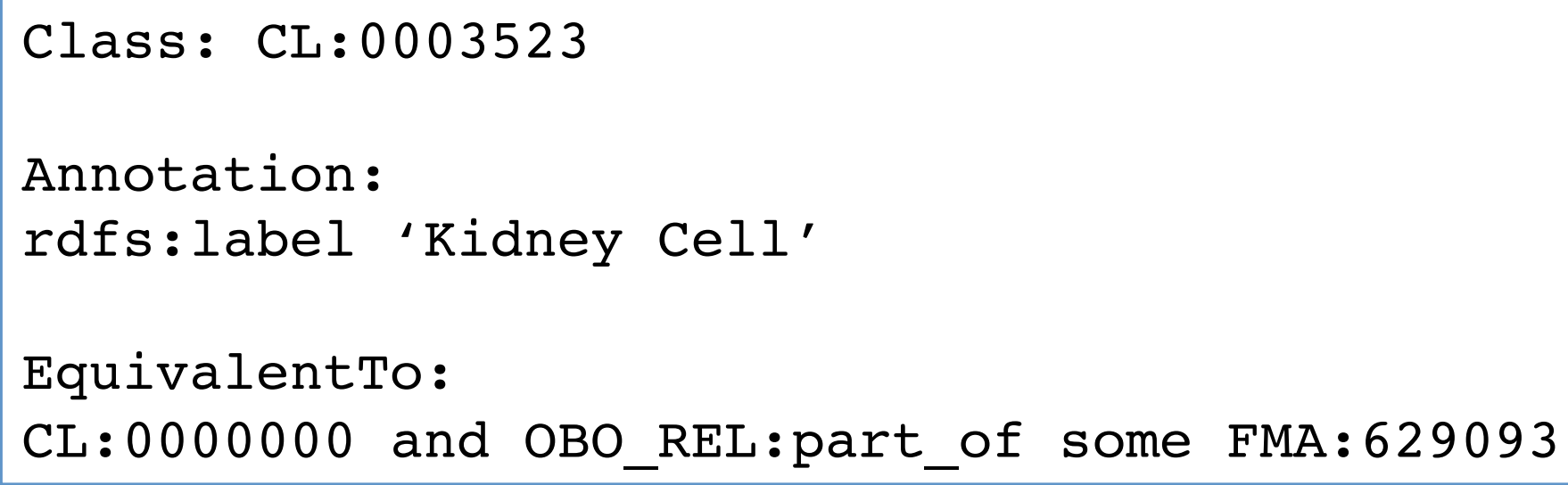




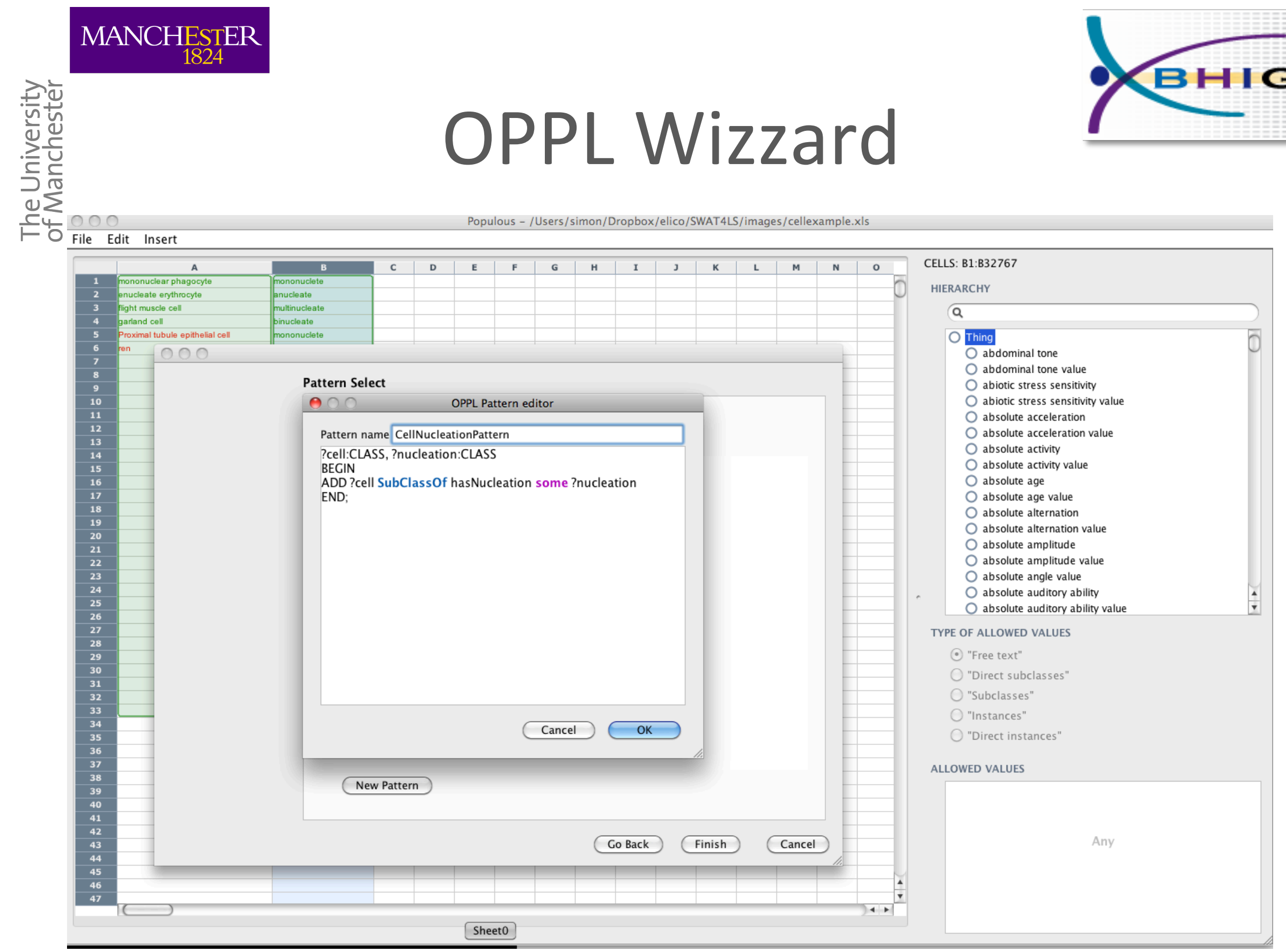




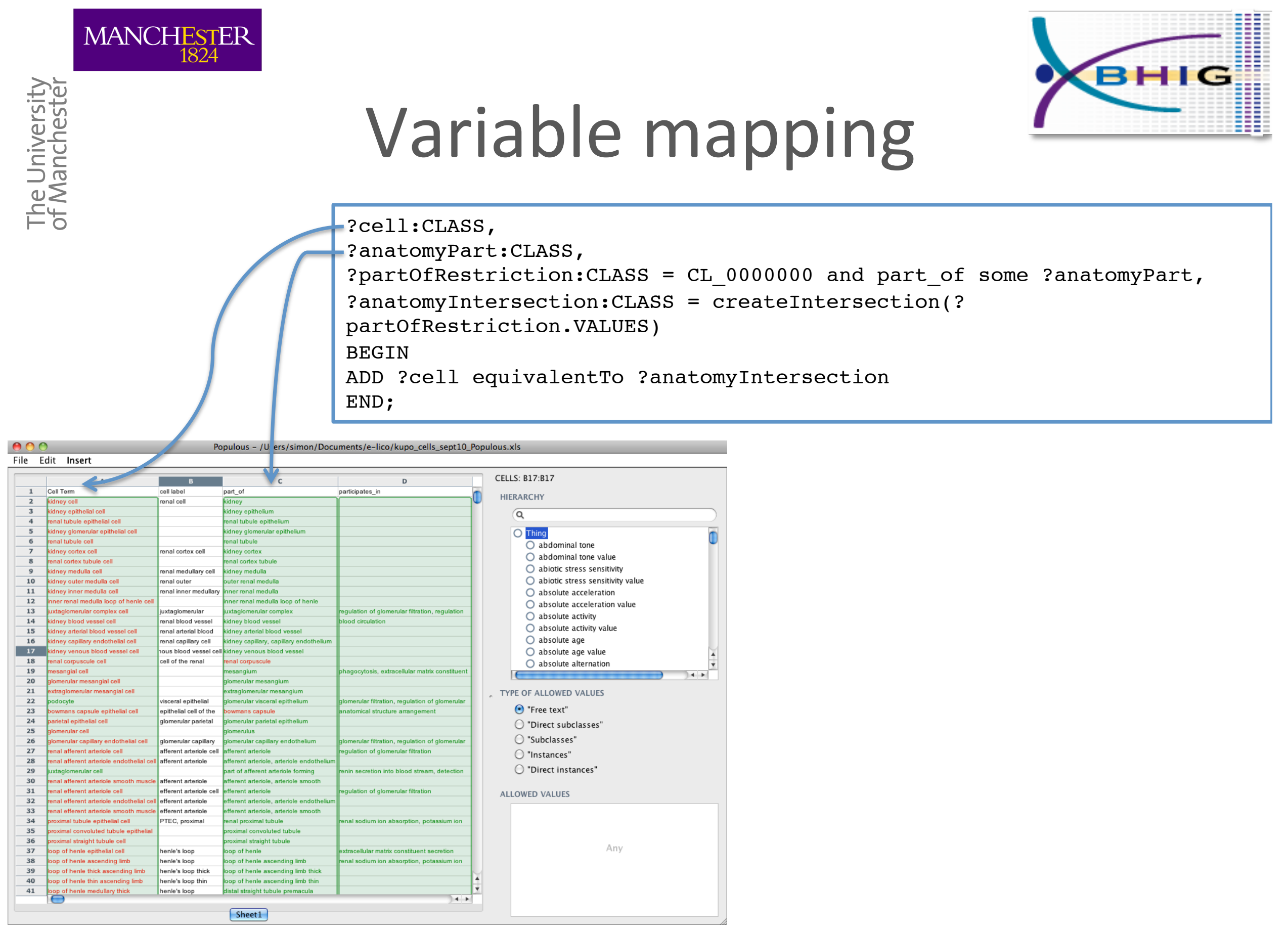



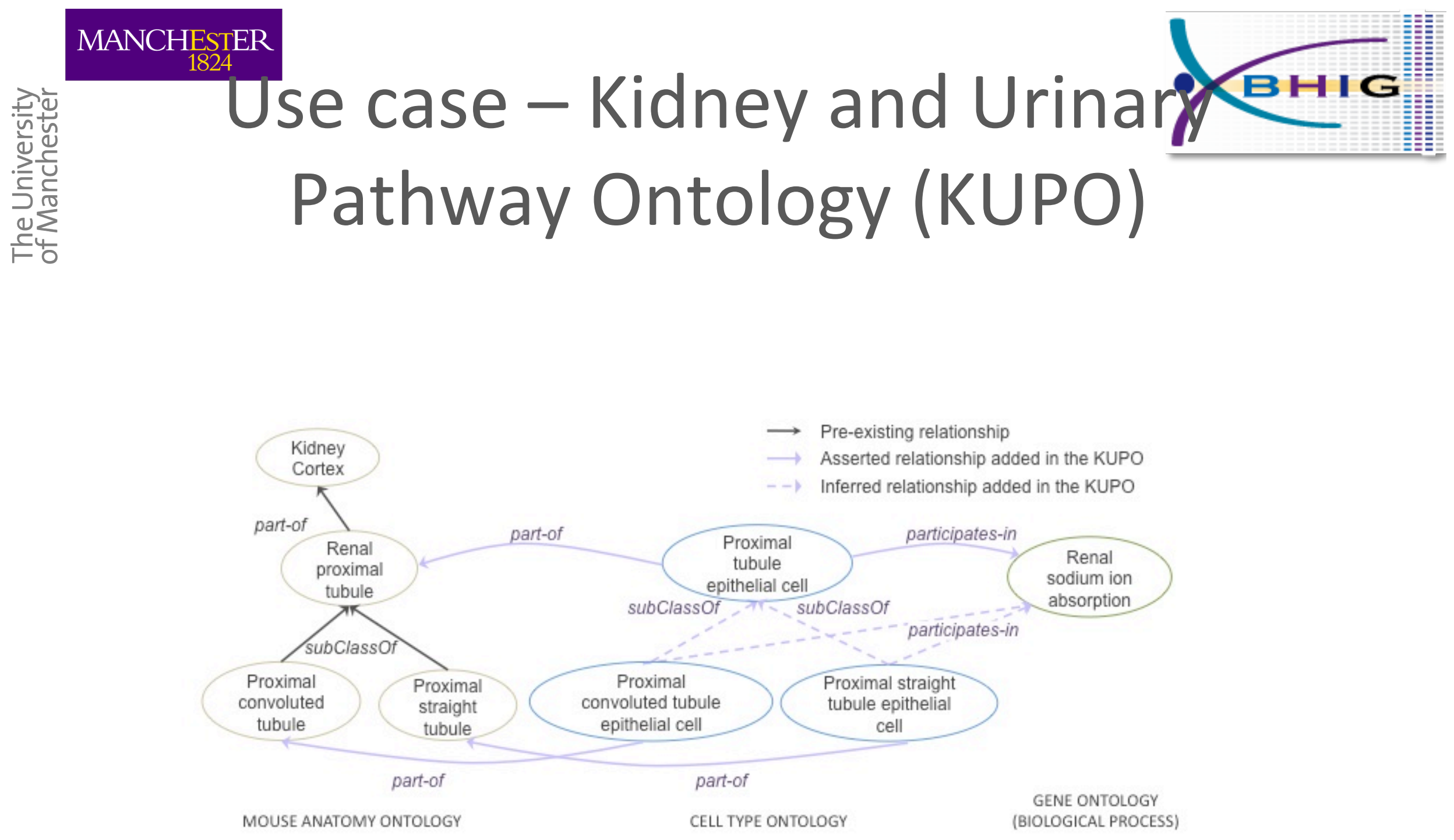
MANCHESTER

1824

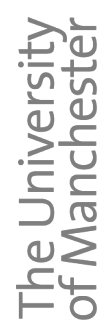

\section{KUPO in Populous}
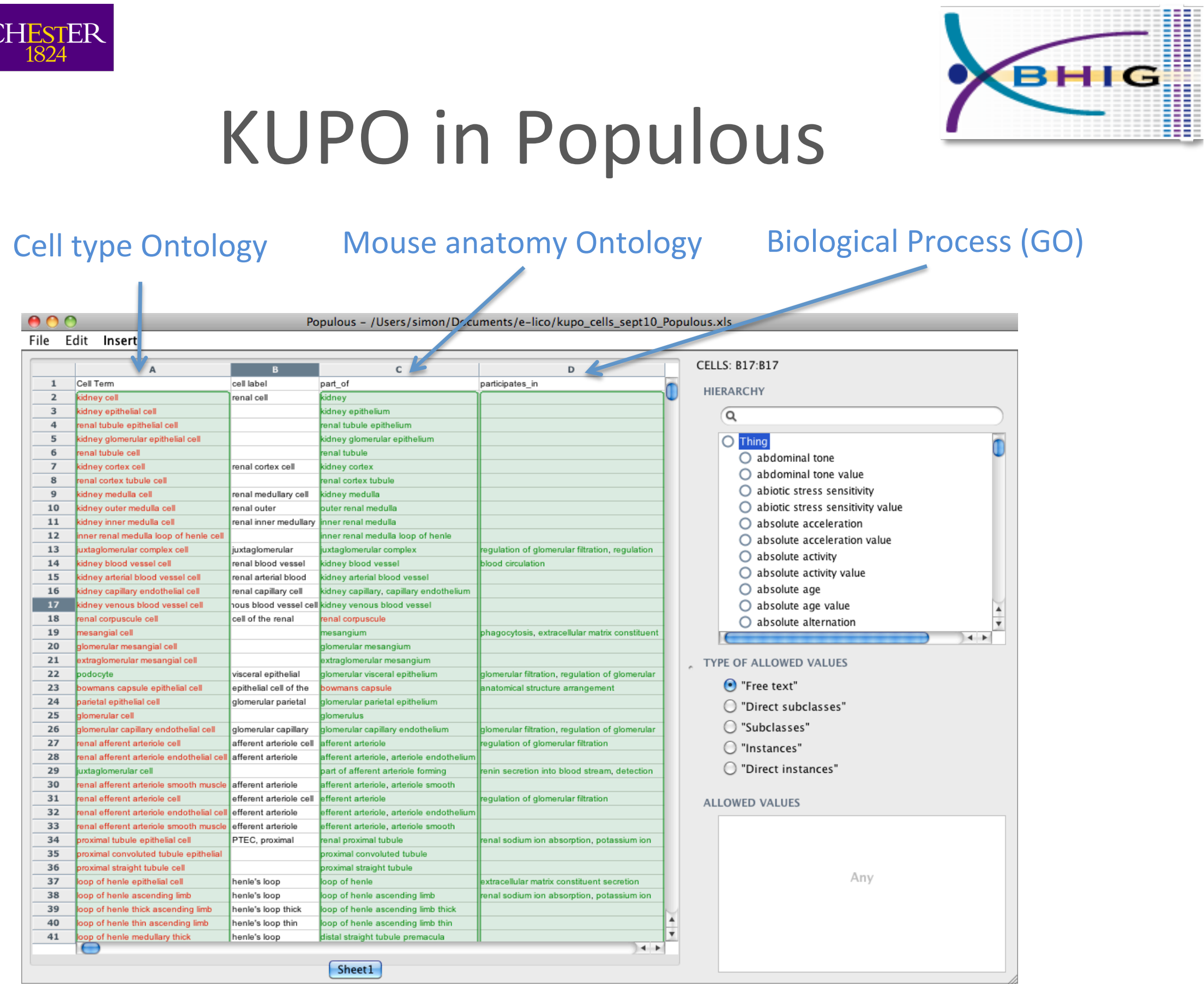
participates_in some 'detection of renal blood flow'

participates_in some 'renin secretion into blood stream'

'juxtaglomerular complex cell'

O'renal afferent arteriole cell'

Iferred anonymous superclasses

participates_in some 'regulation of glomerular filtration

cell

and part of some 'renal corpuscle'

participates_in some 'tubuloglomerular feedback'

- participates in some 'regulation of glomerular filtration

participates_in some 'regulation of glomerular filtration by angiotensin'

cell

and part of some kidney

participates in some 'blood circulation'

Ocell

and part_of some 'kidney blood vesse' 
- Assumes regular patterns

- Developing patterns is hard

- Not always sensible

- Handling exceptions to patterns

- Need special syntax, but how far do you go...

- Regular data (entity-per-row assumption) 


\section{Future plans}

- Mapping Master Support

- Additional syntax

- Ontology Alignment

- Template creation from Protégé OPPL patterns plugin.

- Building KUP knowledge base 


\section{Summary}

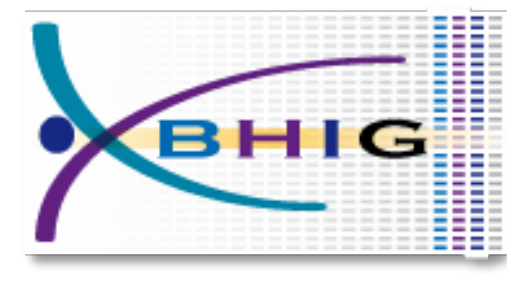

- Populous is for populating templates

- Focus on supporting domain experts

- Expressive pattern language for modeling OWL

- Abstract knowledge from the modeling

- Engaging the experts by stealth! 


\section{Acknowledgments}

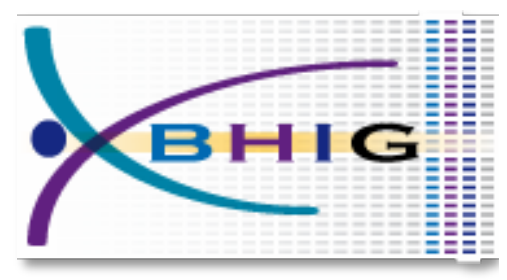

- RightField

Matthew Horridge, Katy Wolstencroft, Stuart Owen,

Carole Goble

- OPPL

Luigi lannone, Mikel Aranguren, Alan Rector, Robert Stevens

- KUPO

Robert Stevens, Julie Klein, Joost Schanstra

- e-LICO

EU-FP7 Collaborative Project (2009-2012)

Theme ICT-4.4: Intelligent Content and Semantics 